Conclusion: Although based on observational data, this work is to our knowledge, the first systematic review and meta-analysis concerned with this subject. SpA and PsA seem to be associated with an increased risk of preterm birth, small for gestational age and elective caesarean section. The analysis of the impact of pregnancy on disease activity in this setting is currently ongoing. References:

[1] Van den Brandt S. Arthritis Res Ther 2017;19(1):64

[2] Ursin K. Rheumatology. 201;57(6):1064-1071.

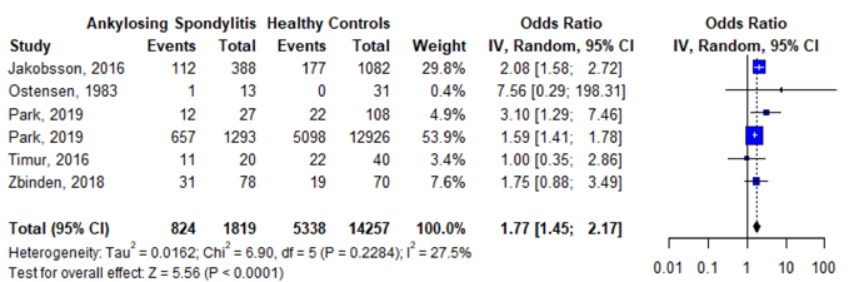

Fig. 1. Association between caesarean section and axSpA

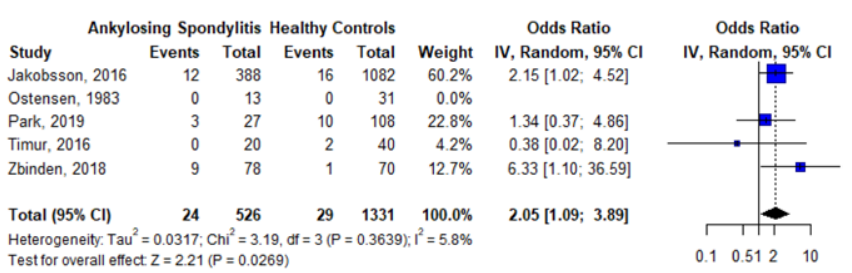

Fig. 2. Association between small for gestational age and axSpA

Disclosure of Interests: SABRINA HAMROUN: None declared, Aghilès Hamroun: None declared, Jean Joël Bigna: None declared, Edem Allado: None declared, Frauke Förger Grant/research support from: Unrestricted grant from UCB, Consultant of: UCB, GSK, Roche, Speakers bureau: UCB, GSK, Anna Moltó Grant/research support from: Pfizer, UCB, Consultant of: Abbvie, BMS, MSD, Novartis, Pfizer, UCB

DOI: 10.1136/annrheumdis-2020-eular.4357

\section{FRI0306 WOMEN WITH AXIAL SPONDYLOARTHRITIS HAVE COMPARABLE RATES OF COMPLICATIONS IN PREGNANCY TO WOMEN IN THE GENERAL POPULATION BUT MORE CAESAREAN DELIVERIES: RESULTS FROM NATIONWIDE CLAIMS DATA}

I. Redeker ${ }^{1}$, A. Strangfeld ${ }^{1}$, U. Marschall ${ }^{2}$, A. Zink ${ }^{1,3}$, X. Baraliakos ${ }^{4} .{ }^{1}$ German Rheumatism Research Centre, Berlin, Germany; ${ }^{2}$ BARMER Institute for Health Systems Research, Wuppertal, Germany; ${ }^{3}$ Charité - Universitätsmedizin Berlin, Berlin, Germany; ${ }^{4}$ Rheumazentrum Ruhrgebiet, Herne, Germany

Background: In contrast to other rheumatic inflammatory diseases, studies on pregnancy outcomes in axial spondyloarthritis $(\operatorname{axSpA})$ are scarce, despite its onset in early adulthood affecting women in their reproductive years.

Objectives: To investigate maternal and infant pregnancy outcomes among women with axSpA compared with population-based controls.

Methods: Taking advantage of a large health insurance dataset, comprising the period $2006-2018$, maternal and infant pregnancy outcomes and delivery outcomes of women with axSpA were assessed and compared with population-based controls (matched by maternal age and calendar year of birth). Odds ratios (ORs) with $95 \%$ confidence intervals (Cls) were calculated using generalised estimating equation analyses.

Results: A total of 611 singleton births among 535 women with axSpA were included in the analysis. The mean age at delivery was 32.5 years. The pharmacological treatment within 12 months prior to and after conception is illustrated in the Figure. Infants of women with axSpA were only slightly more often preterm $(5.2 \%$ vs $4.7 \%)$ and small-for-gestational-age (1.6\% vs $1.1 \%)$ than infants of matched population-based controls, respectively. Caesarean section was performed in $36 \%$ of deliveries among women with axSpA compared with $29.5 \%$ in population-based controls, resulting in a significantly increased risk for receiving caesarean section (OR 1.35; 95\% Cl 1.06-1.73) (Table). The occurrence of pre-eclampsia, preterm birth, and small-for-gestational-age was moderately higher, but not significantly increased, among women with axSpA as compared to population-based controls.

Conclusion: Women with axSpA had no significantly increased risks for adverse maternal or infant pregnancy outcomes compared to non-axSpA women.
However, a significantly increased risk for receiving caesarean section and a tendency for a higher number of preterm deliveries and of small-for-gestational-age infants was observed in women with axSpA.

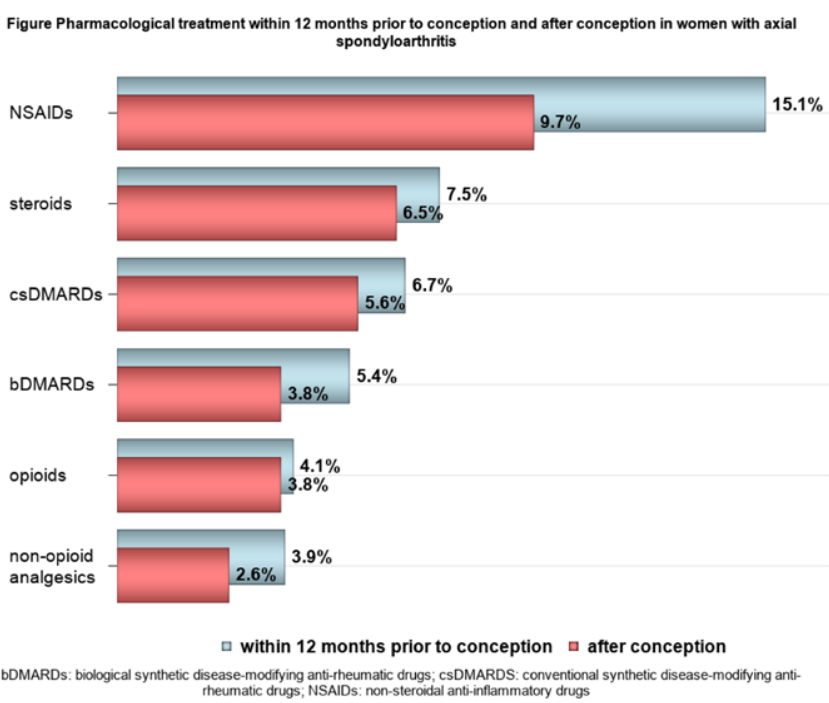

Table. Prevalences and odds ratios with $95 \%$ confidence intervals for adverse pregnancy outcomes

\begin{tabular}{lccc}
\hline & $\begin{array}{c}\text { Pregnancies in } \\
\text { women with axSpA population-based controls } \\
\mathrm{N}=611\end{array}$ & $\begin{array}{c}\text { Pregnancies in } \\
\mathrm{N}=611\end{array}$ & $\begin{array}{c}\text { Odds Ratio } \\
(95 \% \mathrm{Cl})\end{array}$ \\
\hline Preterm birth (< week 37) & $5.2 \%(32)$ & $4.7 \%(29)$ & $1.11(0.66,1.85)$ \\
Gestational week 28-36 & $4.9 \%(30)$ & $4.7 \%(29)$ & $1.03(0.61,1.75)$ \\
Gestational week <28 & $0.3 \%(2)$ & $0.2 \%(1)$ & $2.01(0.18,22.18)$ \\
Small for gestational age & $1.6 \%(10)$ & $1.1 \%(7)$ & $1.43(0.54,3.79)$ \\
Low birth weight $(<2500 \mathrm{~g})$ & $2.8 \%(17)$ & $2.6 \%(16)$ & $1.06(0.53,2.13)$ \\
Exceptionally large baby & $1.1 \%(7)$ & $0.2 \%(1)$ & $7.07(0.87,57.63)$ \\
(birth weight $\geq 4500 \mathrm{~g})$ & & & \\
Pre-eclampsia & $7.5 \%(46)$ & $6.4 \%(39)$ & $1.21(0.78,1.90)$ \\
Assisted vaginal delivery & $4.3 \%(26)$ & $3.1 \%(19)$ & $1.39(0.76,2.56)$ \\
Caesarean section & $36.0 \%(220)$ & $29.5 \%(180)$ & $1.35(1.06,1.73)$ \\
\end{tabular}

axSpA, axial Spondyloarthritis; $\mathrm{Cl}$, confidence interval.

Acknowledgments: We would like to thank the BARMER Statutory Health Insurance for providing data for this study.

Disclosure of Interests: Imke Redeker: None declared, Anja Strangfeld Speakers bureau: AbbVie, BMS, Pfizer, Roche, Sanofi-Aventis, Ursula Marschall: None declared, Angela Zink Speakers bureau: AbbVie, Amgen, BMS, Gilead, Hexal Janssen, Lilly, MSD, Pfizer, Roche, Sanofi Aventis, UCB, Xenofon Baraliakos Grant/research support from: Grant/research support from: AbbVie, BMS, Celgene, Chugai, Merck, Novartis, Pfizer, UCB and Werfen, Consultant of: AbbVie, BMS, Celgene, Chugai, Merck, Novartis, Pfizer, UCB and Werfen, Speakers bureau: AbbVie, BMS, Celgene, Chugai, Merck, Novartis, Pfizer, UCB and Werfen DOI: 10.1136/annrheumdis-2020-eular.5241

\section{FRI0307 DETERMINANTS OF PATIENT-PHYSICIAN DISCORDANCE IN GLOBAL ASSESSMENT IN SPONDYLOARTHRITIS}

S. Azevedo ${ }^{1}$, F. Guimarães ${ }^{1}$, D. Almeida ${ }^{2}$, D. Faria ${ }^{1}$, J. Silva ${ }^{1}$, J. Rodrigues ${ }^{1}$, D. Peixoto ${ }^{1}$, S. Alcino ${ }^{1}$, J. Tavares-Costa ${ }^{1}$, C. Afonso', F. Teixeira ${ }^{1} .{ }^{1}$ Unidade Local de Saúde do Alto Minho, Rheumatology Department, Ponte de Lima, Portugal; ${ }^{2}$ Hospital de Braga, Rheumatology Department, Braga, Portugal

Background: Patient's Global Assessment of Disease Activity (PtGA) and Physician's Global Assessment of Disease Activity (PhGA) are important measures in the evaluation of patients with Spondyloarthritis $(\mathrm{SpA})$, but often provide discordant results. ${ }^{1}$ Both PtGA and PhGA are assessed as part of ankylosing spondylitis disease activity score (ASDAS), that is a measure of axial SpA disease activity endorsed by the Assessment of SpA International Society (ASAS) and Outcome Measures in Rheumatology. ${ }^{2,3}$ In peripheral SpA, although there are no formally validated indexes, the American College of Rheumatology (ACR) and Disease Activity Score 28 (DAS 28) response criteria have shown reliable discriminant characteristics and both include PtGA and PhGA. ${ }^{3}$ The lack 